\title{
The 2012 Flooding in Selected Parts of Isoko South, Delta State: Assessment of Socio-Economic Impacts
}

\author{
Ubachukwu, N.N. \\ Department of Geography Nigerian Defence Academy Kaduna, Kaduna State, Nigeria \\ Emeribe C.N. \\ National Centre for Energy and Environment, Energy Commission of Nigeria, \\ University of Benin, Benin, City, Edo State, Nigeria \\ Email: nechukwu@yahoo.com
}

Doi:10.5901/mjss.2017.v8n1p353

\section{Abstract}

\begin{abstract}
The study investigated the socio-economic impacts of the 2012 flooding in the riverine areas Isoko south Local Government area, Delta State. Two communities Oleh and Aviara which were greatly affected by the flood event were selected for the study. Both purposive and simple random sampling techniques were adopted in the survey. A total of two hundred questionnaire were distributed to household heads, famers, community and religious leaders, one hundred per community. Impacts on building/household property, financial cost of damage, impact on small farm holders, damage on school infrastructures, diseases distributed were used as impact indicators. The study showed that displacement of family members for a period of 3-4months recorded the highest impact with Oleh and Aviara communities scoring impact level of $34 \%$ and $36.6 \%$ respectively. This was followed by submergence of farmland/lost of valuable household property, $27.7 \%$ in Oleh community and 23.6\% Aviara community. Death/major injury during the flood event recorded least impact of $8.5 \%$ in Oleh and $3.2 \%$ in Aviara communities. On the average these impacts were valued at between one and two million naira $(N)$. Analysis of impact on small farm holders showed that monthly income groups between $<50,000$ and 100,000 naira(N) were worst hit by the flood event. These groups are mostly subsistent farmers including snail farmers, poultry owners. The study revealed that schools were closed down for a period of 2-3months while collapsed of bridges was a leading cause of disruption in school activities with impact scores of $22.2 \%$ and $18.8 \%$ in Oleh and Avaira communities respectively. Analysis of disease distribution showed that malaria fever ranked highest, $33.1 \%$ in Oleh and $41.9 \%$ in Avaira respectively. This was followed by Diarrhoea, $22.6 \%$ in Oleh and Typhoid fever, $22.1 \%$ in Aviara. Bearing the losses was a common response approach to the flood disaster in the sampled communities with scores of $30.9 \%$ in Oleh and $27.6 \%$ in Aviara community. Structural modification ranked second with impact score of $16.5 \%$ in Oleh and migration to alternative location $16.3 \%$ in Avaira. Least response approach was construction of Monkey Bridge, $4.2 \%$ in Oleh and $4.1 \%$ in Avaira. Analysis of underlying cause of vulnerability showed that over reliance on government intervention thus doing little was main cause of vulnerability in Oleh, $25 \%$, while in Avaira the main cause of vulnerability was attitude/cultural belief, $20.4 \%$. The geographical locations of these communities also increase their vulnerability to flood by $22.9 \%$ in Oleh and $19.4 \%$ in Aviara. Result of student $t$ test at 0.05 level of significance showed that the impact of the 2012 flooding in study area was similar in terms of damage to physical property, financial cost of impact, damage to school infrastructures and disease distribution. However, significant variation was observed in the two communities in terms of impacts on small farm holders. The study recommends land zoning in the framework of urban planning and regulation of urban development with a view to reducing the vulnerability of future flooding especially in the light recent global warming and climate change.
\end{abstract}

Keyword: Flooding, Socio-economic impact, disease distribution, physical infrastructures, vulnerability

\section{Introduction}

The frequency and magnitude of impacts of weather-related natural hazards in particular flooding on Nigerian society are assuming an increasing dimension. The Nigerian urban slum dwellers and population in coastal areas most are most vulnerable. The coastal zones of the world are mostly populated because of reasons like fertile soil, opportunity for the development of fishing and shipping industry (Mimura, 1999; McGranahan et al 2007; UN, Habitat, 2011; Jena and Mishra; 2011). The IPCC Special Report (2007) on the Regional Impacts of Climate Change showed there would be drastic changes in rainfall patterns in the warmer climate and coastal regions as the Niger Delta may experience 5-6\% increase of rainfall by 2030, which may create frequent high and prolonged floods in the region. According to UN-Water 
(2011), worldwide, there has been rapid growth in number of people killed or seriously impacted by flood disasters. Indeed, the amount of economic damages affects a large proportion of people in low-lying coastal zones or other areas at risk of flooding and extreme weather condition. Unfortunately, the impact in most developing countries is more felt by the urban poor in such a way that recovery is unlikely to be achieved without external aid (Blaikie, 1994). A causal relationship between poverty and vulnerability to natural disaster has been established by authors (Mooser, 1998; Sinha and Lipton 1999; UNDP, 2004). In addition, the elderly, the disabled and children are particularly vulnerable (UN, 2004). Know Risk (2005) observed that studies undertaken show that the economic impact of natural disasters, such as flood shows a marked upward trend over the last several decades. The hazards tend to hit communities in developing countries especially the least developed countries, increasing their vulnerability and setting back their economic and social growth, sometimes by decades. The floods have led to loss of human life, destruction of social and economic infrastructure and degradation of already fragile ecosystems. The study indicates that social impacts include changes in people's way of life, their culture, community, political systems, environment, health and wellbeing, their personal and property rights and their fears and aspirations. Various diseases like waterborne such cholera, dysentery, fever, diarrhea and are common in flood inundated communities. Populations inhabiting the low lying areas of Nigeria have witnessed different degrees of flood events with varying magnitudes of impacts. Over the centuries, these populations have developed different responses approach to flood. However, the 2012 flood which was believed to be caused in part by climate change and release of excess water from Ladgo dam, Republic of Cameroon was the first of its kind the last 40 years in the country. The flood which began in July 2012 killed 363 people, displaced over 2.1 million people across 30 states of the country. Isoko South in Delta State which is a flood prone area due to its geographical location and more so because farming is a major livelihood of its population was affected by the 2012 flood disaster. The aim of this study thus is to examine the socio-economic impacts of the 2012 flooding in selected communities of Isoko south as well as community response methods.

\section{Methodology}

\subsection{Description of study area}

The study area is Isoko south local government area, Delta state with its headquarters at Oleh, Nigeria. The area is one of the two local governments that make up the Isoko region. It lies approximately at latitude $5^{\circ} 22^{\prime} 55.52^{\prime \prime}$ North and longitude $6^{\circ} 12^{\prime} 51.01^{\prime \prime}$ East. The Isoko South Local Government Area covers a low-lying section of the larger Niger Delta Basin, interspersed with streams, canals and rivers (Fig. 1). Isoko south is located in a region of deciduous and evergreen forests, with patches of mangrove forest, as well as a forest reserve along the Aviara clan area. The area is in the tropical rain forest area of the Niger-delta and experiences high rainfall and high humidity most of the year. The climate is equatorial and is marked by two distinct seasons-the Dry and Rainy seasons. The Dry season lasts from about November to April and is significantly marked by the cool "harmarttan" dusty haze from the north-east winds. The Rainy season spans May to October with a brief dry spell in August. The Isoko people migrated historically from Benin, Kingdom Edo State and therefore share some cultural similarities with the state. The Isoko South Local Area produces a large component of the oil and gas resources of Delta State. The population of Isoko South was approximately 227,712 (2006 population census).

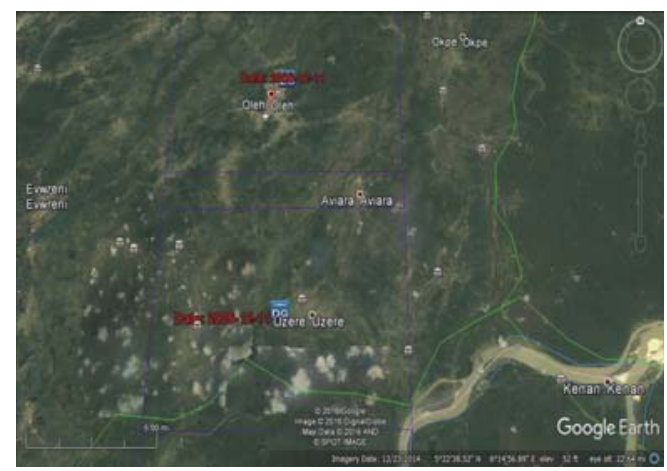

Fig.1: Study Area 
The traditional occupation of the people of Isoko South is fishing and agriculture. There is also the widespread production of palm oil and palm kernels. Limited amount of hunting and fishing is also done. Women form a large proportion of the farming population. They also engage in trade of food crops for cash to meet other basic household needs.

\subsection{Sample collection}

The study adopted a field survey of the inundated areas of some flooded communities in Isoko South, Delta State, Nigeria. The study used primary data source. This was generated through personal observation, questionnaires distribution and oral interview of the people affected during the four (4) months (July-October, 2012) of inundation of the study area. These months were chosen as they coincided with the peak of rainfall in southeastern Nigeria as the peak of inundation. Two communities were selected for the study. These communities are Oleh and Aviara. The choice of these communities was based on willingness of community members to provide information. A total of Two hundred (200) households were randomly sampled from the study area. Household heads, decision makers in the communities (such as, local government counselors, community chiefs, head relief department at the local government secretariat, etc), elders, religious leaders, farmers and youths were targeted in the study, to provide information on the flood occurrences and its impacts on the life of people in the communities. Participatory questionnaire approach was used as a method to access the community's perceptions on the flood occurrences and their impact on the communities' socio-economic lives. Both descriptive and quantitative statistical methods were employed in the analysis and presentation of results. Data were presented in tables and statistical diagrams. The student's t test was used to test for variation in the levels of impacts. The qualitative data was coded and entered in MS Excel before being transported to SPSS (Version 20.0).

\section{Results}

Tables 1-7 illustrate the socio-economic impacts of the 2012 flood events and community responses patterns.

Table 1: Physical Impact of 2012 on household in Isoko south Local Government Area, Delta State

\begin{tabular}{lcccc}
\hline \multirow{2}{*}{ Type of Impact } & \multicolumn{2}{c}{ Oleh Community } & \multicolumn{2}{c}{ Aviara Community } \\
\cline { 2 - 5 } & $\begin{array}{c}\text { Count of } \\
\text { Respondents }\end{array}$ & $\begin{array}{c}\% \text { of } \\
\text { Respondents }\end{array}$ & $\begin{array}{c}\text { Count of } \\
\text { Respondents }\end{array}$ & $\begin{array}{c}\% \text { of } \\
\text { Respondents }\end{array}$ \\
\hline Collapse of building & 10 & 10.6 & 18 & 19.4 \\
Displacement of family members & 32 & 34.0 & 34 & 36.6 \\
Death/injury of Family member & 8 & 8.5 & 3 & 3.2 \\
Submergence of Farmland/lost of & 26 & 27.7 & 22 & 23.6 \\
household properties & 18 & 19.2 & 16 & 17.2 \\
Damaged to businesses & & &
\end{tabular}

Table 2: Estimated financial value of Household Property Damage (N) in Isoko South Local Government Area, Delta State

\begin{tabular}{lcccc}
\hline \multirow{2}{*}{ Value of impact in Naira (N) } & \multicolumn{2}{c}{ Oleh Community } & \multicolumn{2}{c}{ Aviara Community } \\
\cline { 2 - 5 } & Count of Respondents & \% of Respondents & Count of Respondents & \% of Respondents \\
\hline$<100,000.00$ & 14 & 14.6 & 32 & 32.7 \\
$1000,000-1.5$ million & 36 & 37.5 & 36 & 36.7 \\
1.5million -2.5milliom & 32 & 33.3 & 12 & 12.2 \\
2.5million - 3.5million & 12 & 12.5 & 10 & 10.2 \\
Above 3.5million & 2 & 2.1 & 8 & 8.2 \\
\hline
\end{tabular}

Table 3: Estimated Impact of 2012 flooding on small farm holders in Isoko south Local Government Area, Delta State

\begin{tabular}{lcccc}
\hline \multirow{2}{*}{ Value of impact in Naira (N) } & \multicolumn{2}{c}{ Oleh Community } & \multicolumn{2}{c}{ Aviara community } \\
\cline { 2 - 5 } & Count of Respondents & \% of Respondents & Count of Respondents & \% of Respondents \\
\hline$<50,000$ & 26 & 27.1 & 13 & 13.3 \\
$50,000-100,000$ & 16 & 16.6 & 26 & 26.5 \\
$100,000-200,000$ & 20 & 20.8 & 10 & 10.2 \\
$200,000-300,000$ & 18 & 18.8 & 20 & 20.4 \\
$300,000-400,000$ & 10 & 10.4 & 18 & 18.4 \\
Above 400,000 & 6 & 6.3 & 11 & 11.2 \\
\hline
\end{tabular}


Table 4: Impact of 2012 flooding on school Infrastructures in Isoko south Local Government Area, Delta State

\begin{tabular}{lcccc}
\hline \multirow{2}{*}{ Value of impact in Naira (N) } & \multicolumn{2}{c}{ Oleh Community } & \multicolumn{2}{c}{ Aviara community } \\
\cline { 2 - 5 } & Count of Respondents & \% of Respondents & Count of Respondents & \% of Respondents \\
\hline Submergence of school building & 18 & 20 & 16 & 16.7 \\
Disruption of learning activities & 22 & 24.5 & 22 & 22.9 \\
Fear of another flooding & 6 & 6.7 & 11 & 11.5 \\
Collapse of bridge & 20 & 22.2 & 18 & 18.8 \\
Road being impassable & 16 & 17.8 & 17 & 17.7 \\
Damage to school infrastructures & 8 & 8.8 & 12 & 12.5 \\
\hline
\end{tabular}

Table 5: Diseases experienced by household members during the 2012 Floods in Isoko south, Delta State

\begin{tabular}{lcccc}
\hline \multirow{2}{*}{ Disease Type } & \multicolumn{2}{c}{ Oleh Community } & \multicolumn{2}{c}{ Aviara community } \\
\cline { 2 - 5 } & Count of Respondents & \% of Respondents & Count of Respondents & \% of Respondents \\
\hline Diarrhoea & 21 & 22.6 & 8 & 9.3 \\
Skin infection & 13 & 13.9 & 9 & 10.5 \\
Malaria & 33 & 35.5 & 36 & 41.9 \\
Measles & 6 & 6.5 & 2 & 2.3 \\
Typhoid Fever & 16 & 17.2 & 19 & 22.1 \\
Tetanus Infection & 4 & 4.3 & 12 & 13.9 \\
\hline
\end{tabular}

Table 6: Response Methods to 2012 flooding in Isoko south Local Government Area, Delta State

\begin{tabular}{lcccc}
\hline \multirow{2}{*}{ Value of impact in Naira (N) } & \multicolumn{2}{c}{ Oleh Community } & \multicolumn{2}{c}{ Aviara community } \\
\cline { 2 - 5 } & Count of Respondents & \% of Respondents & Count of Respondents & \% of Respondents \\
\hline Bear the loss & 30 & 30.9 & 27 & 27.6 \\
Alternative location & 8 & 8.2 & 16 & 16.3 \\
Government intervention & 12 & 12.4 & 8 & 8.2 \\
Structural modification & 16 & 16.5 & 12 & 12.2 \\
Change of livelihood & 8 & 8.2 & 16 & 16.3 \\
Construction of canals & 10 & 10.3 & 9 & 9.2 \\
Raising of ground surface & 9 & 9.3 & 6 & 6.1 \\
Construction of monkey bridge & 4 & 4.2 & 4 & 4.1 \\
\hline
\end{tabular}

Table 7: Underlying cause of vulnerability to the 2012 flood impact in Isoko south, Delta State

\begin{tabular}{lcccc}
\hline \multirow{2}{*}{ Vulnerability Indicator } & \multicolumn{2}{c}{ Oleh Community } & \multicolumn{2}{c}{ Aviara community } \\
\cline { 2 - 5 } & Count of Respondents $\%$ of Respondents & Count of Respondents \% of Respondents \\
\hline Occupation in flood prone area & 22 & 22.9 & 19 & 19.4 \\
Poverty / Lack of alternative & 16 & 16.7 & 11 & 11.2 \\
Level of literacy & 14 & 14.6 & 18 & 18.4 \\
Reliance on government/community intervention & 24 & 25 & 16 & 16.3 \\
Attitude/cultural belief & 8 & 8.3 & 20 & 20.4 \\
Small businesses & 12 & 12.5 & 14 & 14.3 \\
\hline
\end{tabular}

\section{Discussion}

The severity of the 2012 flood shows that displacement of family members for the period of three-four month was the greatest impact in Isoko south, while submergence of farmland/lost of household property ranked second in terms of impact. Least impact was recorded for death/injuries. In Oleh community, damage to businesses was also a significant impact while collapse of buildings was also a very significant impact in Aviara community. These include residential and commercial buildings, bungalows, duplexes and storey buildings. The low response to death/injury in the both communities maybe attributed to the fact that the inhabitants of the study area are used to swimming even as early as 7 years. The study found that the voluntary services of divers also reduced the number of mortality. Only few deaths by disabled persons were recorded. Relocation to government relief camp and family friend in the upland areas was the two main available options. The financial cost of these damages ranged from lowest amount of fifty thousand Naira $(50,000$ 
N) to highest value of 3.5 million naira. However, greatest impact was on the category of 100,000-1.5million Naira. The group under this category is mostly state civil servants and medium farm holders.

The level of damage on small-medium farm holders by the 2012 floods is summarized in table 3 . In Oleh community, most of the impact was experienced by small farm holders' mostly subsistent farmers who supplement civil service Job with farming. In Aviara such was not the same as the impact on agriculture was more on medium farm holders. Generally however small farmer holders were most affected. The implication is such that since crop production/ snail farming, live stock farming and fish farming are the main source of livelihood and food, continued exposure to floods will exacerbate their vulnerabilities as most of the respondents were willing to return home after the flood. All the respondents showed closure of school during the 4 months of flood inundation. Furthermore, $22.2 \%$ of the sampled households in Oleh indicated that collapse of connecting bridges was an major cause of disruption in learning activities. They were also reported cases complete submergence school infrastructure/damage of teaching equipment. The disruption in educational activity was also attributed to various reasons such as road being impassable. The study found that rivers and boreholes were the most common water sources that communities used for domestic uses. Nevertheless malaria fever was the common sickness during the 4months of flood inundation as stagnant water became a breeding habitat for mosquitoes. The study revealed outbreaks of diarrhea and typhoid fever. This may be attributed to contamination from wastes, solid and sewage from burst septic tanks/pit latrines. The study found that the most common adjustment to the 2012 flooding in the study area was simply to suffer and bear the losses. The household or business owners bore the financial consequences of the flood disaster. The psychological and social impacts fall on the victims. This has negative effects as most of the flood affected persons reported to be battling with the thought of suicide. The fact that building Monkey Bridge ranked lowest in terms of response methods adopted by members of communities showed that most of the flood affected persons were of low income earning group. Results of student $t$ test at 0.05 level of significance showed that the impact of the 2012 flooding in study area was similar in terms of damage to physical property, financial cost of impact, damage to school infrastructures and disease distribution. However, significant variation was observed in the two communities in terms of impacts on small farm holders.

\section{Conclusion and Recommendations}

The study revealed that the 2012 floods had adverse impact on the socio-economic status of livelihoods of people in in Oleh and Aviara communities, Isoko South Delta State whose traditional occupation are farming and fishing. It is also evident that the locations of these communities, their economic status and over dependence on government intervention were underlying causes of the people's vulnerability and this poses a challenge for reducing or minimizing vulnerability. Although only few health facilities were damaged due to the floods, accessibility to available health services was a problem due to infrastructure (Roads and Bridges) damage. School activities were also disrupted due to impassable roads, submergence of school building and fear from residents of another flood disaster. It was clear that households cope differently during the 2012 flood event. However, the most common strategy was bearing the losses by victims of the flood. Level of poverty also acted to prevent households from building concrete bridges, rather there was a general understanding than government should be responsible for flood control/abatement a situation which makes people less prepared for disaster. In the light of the above the study recommends that State government and relevant key stakeholders should engage communities in order for them to move permanently to higher grounds as most of the flood affected persons expressed the willingness to relocate if alternative livelihoods/basic social amenities such as; schools, hospitals, infrastructure are provided. There also need for land zoning in the framework of urban planning and regulation of urban development with a view to reducing the vulnerability of future flooding especially in the light recent global warming and climate change.

\section{References}

Blaikie, P., Cannon, T., Davis, I., and Wisner, B. (1994): At risk: natural hazards, people's vulnerability and disasters. London: Routledge IPCC (2007): Climate Change 2007: Impacts, Adaptation, and Vulnerability. Contribution of Working Group II to the Fourth Assessment Report of the Intergovernmental Panel on Climate Change Cambridge University Press, UK, 976pp

Jena K.C and Mishra M.R (2011): Effect of Global Warming and Climate Change on Coastal Zones and Sea Level Orissa Review September-October pp 83-94

Know Risk, (2005): United Nations (p.74), Genera, Switzerland

McGranahan, G. Balk, D., and Anderson, B (2007): "The rising tide: assessing the risks of climate change and human settlements in low elevation coastal zones". Environment and Urbanization 19, 17- 37

Minura N (1999): Vulnerability of island countries in the South Pacific to sea level rise and climate change. Clim. Res Vol. 12: 137-143 
Moser C (1998): the Asset Vulnerability Framework: Reassessing Urban Poverty Reduction Strategies World Development vol. 26(1) pp 1-19

Sinha S and Lipton M (1999): Damaging fluctuation, Risk and Poverty: A Review Background paper for the world development report 2000/2001, poverty research unit, university of Sussex

UN, (2004): Guidelines for reducing flood losses, UN inter-agency secretariat for the international strategy for disaster reduction, Geneva. 83pp

UNDP (2004): Reducing Disaster Risk: A challenge for development, a Global report, UNDP Bureau of crisis prevention and recovery, New York

UN-Habitat. (2011): Cities and climate change: Policy directions. Global report on human settlements 2011 (Abridged Edition). UNHabitat, Earthscan, London

UN-Water. (2011): Cities coping with water uncertainties. Media Brief, UN-Water Decade Programme on Advocacy and Communication 